\title{
Thermomechanical Behavior and Corrosion Resistance of a 316 L Austenitic Stainless Steel
}

\author{
Rafael P. Ferreira, Carmem C. F. Nascimento, Gedeon S. Reis, Eden S. Silva, Samuel F. Rodrigues \\ Graduate Program in Materials Engineering, Federal Institute of Education, Science and Technology of Maranhão (IFMA), Sao Luis, Brazil \\ Email: rafael.ferreira@ifma.edu.br
}

How to cite this paper: Ferreira, R.P., Nascimento, C.C.F., Reis, G.S., Silva, E.S. and Rodrigues, S.F. (2020) Thermomechanical Behavior and Corrosion Resistance of a 316 L Austenitic Stainless Steel. Materials Sciences and Applications, 11, 217-233.

https://doi.org/10.4236/msa.2020.114015

Received: January 11, 2020

Accepted: March 29, 2020

Published: April 1, 2020

Copyright $\odot 2020$ by author(s) and Scientific Research Publishing Inc. This work is licensed under the Creative Commons Attribution International License (CC BY 4.0).

http://creativecommons.org/licenses/by/4.0/

\begin{abstract}
Hot-formed components are constantly exposed to hostile environments with corrosive substances. Microstructural changes caused by thermomechanical processing can be predicted to increase the corrosion resistance of austenitic stainless steels. The objective of this study is to understand the relationship between the dynamic softening mechanisms and corrosion resistance, thus optimizing the hot-forming process. In the current work, the dynamic recrystallization (DRX) behavior of AISI $316 \mathrm{~L}$ austenitic stainless steel was studied in the temperature range of $1273-1423 \mathrm{~K}$ and strain-rate range of 0.1 $5.0 \mathrm{~s}^{-1}$ using physical simulation. Subsequently, potentiodynamic polarization tests and scanning electron microscopy were performed on the hot-deformed samples to investigate the influence of temperature and strain-rate on the corrosion resistance and mechanical properties. The results indicated that the DRX fractions increased under low-temperature and high strain-rate conditions, resulting in grain refinement. The potentiodynamic polarization tests indicated that the dynamically recovered samples demonstrated high resistance to corrosion compared with the DRX samples. The best route found for the investigated alloy was for the strain to be applied at a temperature of 1423 $\mathrm{K}$ and a strain rate of $0.1 \mathrm{~s}^{-1}$.
\end{abstract}

\section{Keywords}

316 L Austenitic Stainless Steel, Softening Phenomena, Corrosion

\section{Introduction}

Various industries require increasingly versatile materials for very specific applications. Stainless steel possesses interesting characteristics such as weldability, mechanical properties, corrosion resistance, and wide working-temperature range [1] [2]. The AISI $316 \mathrm{~L}$ austenitic stainless steel has high corrosion resis- 
tance, good ductility, and excellent weldability over a wide range of temperature [3]. With these characteristics, these alloys have been in demand for applications in pipelines, heat exchangers, hospital equipment, cryogenic valves, and similar purposes. However, before these components are manufactured, they are thermomechanically processed by hot rolling or forging to obtain the desired geometries [4]. Additionally, the presence of carbon in the solution is undesirable because it causes the formation of $\mathrm{M}_{23} \mathrm{C}_{6}$ and intermetallic compounds such as sigma $(\sigma)$, chi $(\chi)$, and laves $(\eta)$ phases. Although the $316 \mathrm{~L}$ steel contains minimal amount of carbon, this presence can lead to the formation of these phases when processed at high temperatures, which induce sensitization and intergranular corrosion of the material [5] [6] [7]. Mechanical stresses coupled with corrosion are the main factors in equipment failure, which can result in material damage, human harm, environmental damage, damage to public health, and major economic damage. Manufacturing of more corrosion-resistant components requires a huge world economic cost, but improvement in this material property is directly linked to its microstructure, which in turn is directly related to its processing. Physical simulation of thermomechanical processing can predict the deformation parameters that can be used in the industry to obtain microstructures that demonstrate good mechanical properties and higher corrosion resistance.

The hot-deformation behavior of 316, $316 \mathrm{~L}$, and $316 \mathrm{~L}$ N-type stainless steel has been widely studied [8] [9] [10]. The corrosion resistances of 316, $316 \mathrm{~L}$, and 316 L N-type stainless steel have also been extensively researched [11] [12] [13]. However, report on the relationship between the hot-deformation behavior and corrosion resistance of materials has been scarce, particularly that of the $316 \mathrm{~L}$ austenitic stainless steel. This is important because the microstructural evolution during the thermomechanical process influences the corrosion resistance of alloys [14] [15]. Moreover, during industrial hot forming, the best mechanism for controlling the microstructural evolution is dynamic recrystallization (DRX) [16]. Knowledge on DRX kinetic models was sought to predict the volume fractions [17]. Process parameters such as strain rate, deformation temperature, and strain influence the DRX behavior and chemical composition [18]. The DRX process results in very refined microstructure and enhanced strength of alloys.

As previously mentioned, some studies have investigated the relationship between the hot-forming process routes and corrosion resistance of fabricated parts. In general, grain size, presence of precipitates, and sample homogeneity after processing are major factors that define the susceptibility to corrosion of the processed components. Studies on $\mathrm{Mg}-9 \mathrm{Li}-3 \mathrm{Al}-2 \mathrm{Sr}-2 \mathrm{Y}$, which is a double-phase alloy, were conducted to investigate the behavior of a microstructure during thermomechanical processing. Constant thermal cycling during processing can lead to deleterious phase formation or transformation. Additionally, the Mg-Li alloys have localized corrosion sensitivity at the $\alpha-\mathrm{Mg} / \beta$ - $\mathrm{Li}$ interfaces. The study demonstrated that Al4Sr phases remained after X-ray diffraction, which was continuously disposed along the grain boundaries. These phases 
were responsible for improving the corrosion resistance of the structured duplex $\mathrm{Mg}-\mathrm{Li}$ alloy, as verified by electrochemical testing [15]. Other materials were studied, such as the steel used in pipelines, which were investigated to verify the influence of hot-forming temperature on corrosion susceptibility. High-strength low-alloy steel with $0.766 \mathrm{wt} \%$ manganese was subjected to hot processing at two temperatures, namely, $800^{\circ} \mathrm{C}$ and $1100^{\circ} \mathrm{C}$, and strain rates of $0.1,1$, and $10 \mathrm{~s}^{-1}$. The optimized hot-deformation route determined the prescribed strain applied at $800^{\circ} \mathrm{C}$ and $0.1 \mathrm{~s}^{-1}$ because it promoted lower susceptibility to corrosion than the other routes. The sample exhibited a completely recrystallized and homogeneous grain structure, which was responsible for the best corrosion resistance [19].

In another study, hot-forming simulations of Co-Cr-Mo-Cu alloys were carried out using isothermal compression tests at strain temperatures from $950^{\circ} \mathrm{C}$ to $1150^{\circ} \mathrm{C}$ and strain rates from 0.008 to $5 \mathrm{~s}^{-1}$. The microstructure of the samples after processing was investigated to verify the influence of hot deformation on the corrosion susceptibility. As known, the average grain size is fully sensitive to temperature and strain-rate variations. The study indicated an increase in the grain size with increasing strain temperature but a decrease with increasing strain rate. Under these conditions, the results of the electrochemical tests clearly indicated that the deformation at a temperature of $1050^{\circ} \mathrm{C}$ was found to promote the formation of a microstructure that was less susceptible to corrosion. At deformation temperatures between $1100^{\circ} \mathrm{C}$ and $1150^{\circ} \mathrm{C}$, a slight reduction in the corrosion resistance occurred. According to the author, the best-recrystallized grain structures with thick grain boundaries were formed at $1100^{\circ} \mathrm{C}$ and $1150^{\circ} \mathrm{C}$, and an increase in the amount of grain boundaries led to an increase in anodic reactions, causing a decrease in the corrosion resistance. In summary, a large number of grain boundaries contributed to a low corrosion resistance. An optimal condition was found in the temperature range from $1050^{\circ} \mathrm{C}$ to $1100^{\circ} \mathrm{C}$ and strain rate from 0.008 to $0.2 \mathrm{~s}^{-1}$ where a completely recrystallized and homogeneously distributed microstructure was obtained [20].

However, determining the optimum combination of strain rate and temperature from the industrially feasible ranges of these parameters is necessary. For example, the DRX grain size decreases with the decrease in temperature and/or increase in strain rate. These relationships can be expressed by the Zener-Hollomon parameter (Z) [21] [22]. A thermomechanical physical simulation using hot-torsion tests can predict the deformation parameters that can be used in the industry to obtain microstructures with good mechanical properties and higher corrosion resistance [23]. This anticipation ensures economy in the process; thus, any simulation carried out in laboratories can reduce the costs of its realization in an industrial plant. Therefore, in the present study, physical simulations of the hot-working processes were carried out by varying the parameters such as temperature, strain, and strain rate according to industrial conditions. Plastic-flow curves were obtained to determine the stress-ratio equivalent versus equivalent deformation and the constitutive equation to predict the kinetics of 
the DRX behavior based on the hot-deformation parameters as well as the effects of DRX, deformation temperature, and strain-rate temperature during hot deformation on the corrosion resistance of $316 \mathrm{~L}$ austenitic stainless steel. The results are presented and discussed.

\section{Materials and Methods}

The chemical composition of the alloy used in this study had $16.60 \mathrm{wt} \% \mathrm{Cr}$, $12.00 \mathrm{wt} \% \mathrm{Ni}, 2.11 \mathrm{wt} \% \mathrm{Mo}, 1.40 \mathrm{wt} \% \mathrm{Mn}, 0.078 \mathrm{wt} \% \mathrm{~N}, 0.039 \mathrm{wt} \% \mathrm{P}, 0.025 \mathrm{wt} \%$ $\mathrm{C}$ and the balance iron. Prior to receipt, the material was solubilized at $1303 \mathrm{~K}$ for $1 \mathrm{~h}$ and subsequently water cooled. The microstructure consists of equiaxed grains with initial average grain size of $35 \mu \mathrm{m}$. The torsion test specimens with a gauge section of $11.00 \mathrm{~mm}$ length and $8.00 \mathrm{~mm}$ diameter were machined. The isothermal hot-torsion tests were performed on a G-III hot-torsion testing machine, initiating with preheating to $1473 \mathrm{~K}$ and held for $5 \mathrm{~min}$ to homogenize the microstructure. Thereafter, the samples were then cooled at $276.3 \mathrm{~K} \cdot \mathrm{s}^{-1}$ to the deformation temperatures of $1273,1323,1373$, and $1423 \mathrm{~K}$, held for $30 \mathrm{~s}$ and deformed at strain rates of $0.1,0.5,1.0$, and $5.0 \mathrm{~s}^{-1}$ for a deformation of 3.5. The samples were quenched in water immediately after deformation to investigate the microstructure. A k-type thermocouple spot welded onto the samples was used to measure and control the temperature. The torque and the number of revolutions were recorded and converted to von Mises equivalent stress and equivalent strain $\left(\sigma_{e q}\right.$ and $\left.\varepsilon_{e q}\right)$, according to the methodology shown by Fields and Backofen [24].

The flow curves normally reveal a single peak, value of the peak stress $\left(\sigma_{p}\right)$, followed by a gradual drop towards a constant value, steady state $\left(\sigma_{s s}\right)$. However, some test flow curves no showed a single peak, therefore the values of the peak $\left(\sigma_{p}\right)$, critical $\left(\sigma_{c}\right)$ and saturation $\left(\sigma_{s a t}\right)$ stresses can be determined from curves of the strain hardening rate $(\theta)$ against stress $(\sigma)$. In order to avoid noise, irregularities and fluctuations, this technique requires the differentiation of the smoothed stress-strain curve, as a simplification, was obtained by fitting a higher order polynomial using the Origin 9.0. Afterward the peak, a flow softening region can be represented by Avrami relation, Equation (1).

$$
X_{s}=\frac{\sigma_{\text {sat }}-\sigma}{\sigma_{\text {sat }}-\sigma_{s s}}=1-\exp \left(-K t^{n}\right)=1-\exp \left(-0.693\left(\frac{t}{t_{0.5}}\right)^{n}\right)
$$

Here, $k$ is the Avrami constant, and $n$ the time exponent, $t_{0.5}$ is a characteristic time and $X_{s}$ is the softening volume fraction along the applied deformation.

Metallographic observations were performed on tangential sections at a depth of $250 \mu \mathrm{m}$ below the gauge surface. Grinding and polishing of the specimens were conducted and the microsections were subjected to electrolytic etching in $65 \%$ nitric acid $\left(\mathrm{HNO}_{3}\right)$ at a current density of $1 \mathrm{~A} / \mathrm{cm}^{2}$ and time about $30 \mathrm{~s}$. The microstructure was observed and recorded using an optical microscope and auxiliary software. The average grain size was determined the method according to the American Society for Testing and Materials E112-88 standard [25]. The 
competition between Dynamic Recovery (DRV) and DRX were investigated using scanning electron microscopy (SEM) in which energy-dispersive X-ray spectroscopy analyses were performed to identify the existing phases. Meanwhile, thermochemical calculations were performed using Fact-Sage FSsteel database 5.6.

Potentiodynamic polarization tests were performed after the hot-torsion tests. The samples were prepared in an area of approximately $1.0 \mathrm{~cm}^{2}$, which was welded using a $1.5-\mathrm{mm}^{2}$ rigid conductive wire and later mounted using epoxy resin. All samples were conventionally polished by progressive grinding using wet abrasive SiC sandpapers with grit numbers between $\# 180$ and \#1200. The anodic polarization curves were obtained using a potentiostat from AUTOLAB (Model AUT86425), implemented using the NOVA software from Metrohm Autolab B, Version 1.11.0. The samples were immersed in a 3.5\% solution of sodium chloride $(\mathrm{NaCl})$ at room temperature $(298 \mathrm{~K})$. During the tests, the open-circuit potential (OCP) was determined as a function of time (OCP versus time) until potential stabilization. Subsequently, the potentiodynamic polarization curves were obtained to estimate the corrosion and pitting potential. The scanning region in this test was measured at $-1.0 \mathrm{~V}$ as a function of the OCP up to $0.5 \mathrm{~V}$ versus the saturated calomel electrode (SCE) with a scanning speed of $1.0 \mathrm{mV} / \mathrm{s}$ [11]. After the polarization test, the samples were characterized using SEM. The corrosion potential $\left(E_{c o r r}\right)$ and pit potential $\left(E_{p i t}\right)$ were determined according to the Tafel method [25].

\section{Results}

\subsection{Flow Curves Behavior}

The true stress-strain curves of the $316 \mathrm{~L}$ austenitic stainless steel obtained at various strain rates at deformation temperatures of $1273,1323,1373$, and $1423 \mathrm{~K}$ are shown in Figure 1. We can observe that almost all flow curves in this figure exhibit similar characteristics. Initially, all curves showed that while deforming, the stress is elevated rapidly on work-hardening stage up to a peak stress followed by a descending stress, softening region, until reaching a steady state or not. The level of flow stress is higher in higher strain rates and lower temperatures, for example, $5.0 \mathrm{~s}^{-1}$ at $1273 \mathrm{~K}$. In contrast, the level of flow stress is lower in lower strain rates and higher temperatures, for example, $0.1 \mathrm{~s}^{-1}$ at $1423 \mathrm{~K}$. This behavior indicated that the flow stress decreases with the increase of temperature and the decrease of strain rate.

\subsection{Constitutive Modeling}

The processing parameters and its responses obtained from torsion can be used to determine the material constant of the constitutive equation that is employed in academic and industrial simulations to predict the metal behavior during hot working. The influence of strain rate and temperature on steady state flow stress and peak stress could be satisfactorily expressed with an Arrhenius type rate 


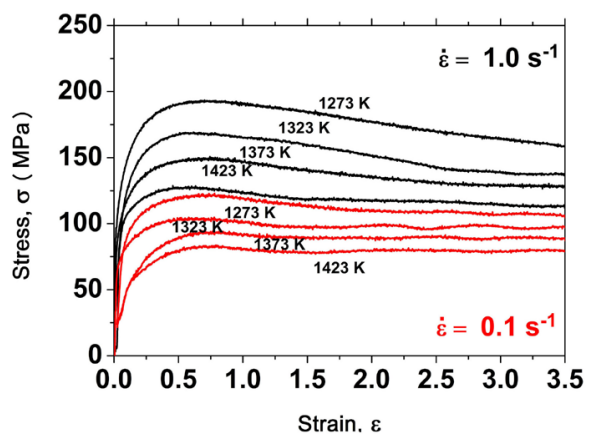

(a)

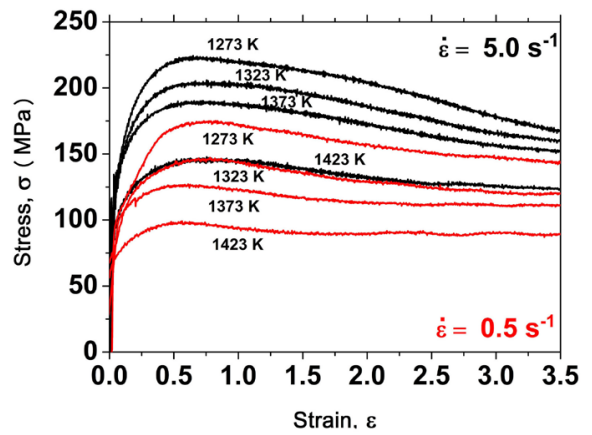

(b)

Figure 1. Stress-strain curves obtained from the thermomechanical simulations. (a) 0.1 and $1.0 \mathrm{~s}^{-1}$; (b) 0.5 and $5.0 \mathrm{~s}^{-1}$.

equation proposed by Sellars and Tegart [26] in hyperbolic-sine form. To correlate the date at different temperatures and strain rates, temperature strain rate parameter $Z$ (Zener-Hollomon parameter) given by relation was introduced into Equation (2):

$$
Z=\dot{\varepsilon} \exp \left(\frac{Q_{\text {def }}}{R T}\right)=A\left[\sinh \left(\alpha \sigma_{p}\right)\right]^{n}
$$

where $\dot{\varepsilon}$ is the strain rate, $Q_{\text {def }}$ is the deformation activation energy (J/mol), $R$ is the universal gas constant $[8.31 \mathrm{~J} /(\mathrm{mol} \cdot \mathrm{K})], T$ is the absolute temperature $(\mathrm{K})$, $Z$ is the Zener-Hollomon parameter, and $\sigma_{p}$ is the peak stress (MPa). These are constants that depend on variables $A, \alpha$, and $n$ of the material. As a simplification, the stress exponent $(n)$ and the activation energy $\left(Q_{d e f}\right)$ was determined as proposed by Laasraoui and Jonas [27]. Equation (3) was originated after mathematical manipulations were performed in Equation (2) to facilitate the determination of the variables of interest.

$$
\ln \dot{\varepsilon}+\frac{Q_{d e f}}{R T}=n \ln \left[\sinh \left(\alpha \sigma_{p}\right)\right]+\ln A
$$

For a specific temperature, by partially differentiating Equation (3), stress exponent $n$ can be expressed in terms of the following:

$$
n=\left.\frac{\partial \ln \dot{\varepsilon}}{\partial \ln \left[\sin \left(\alpha \sigma_{p}\right)\right]}\right|_{T}
$$


Similarly, for a constant strain rate, partial differentiation of Equation (3) can yield the expression of activation energy $Q_{\text {def }}$ which is expressed as follows:

$$
Q_{\text {def }}=\left.\frac{n R \partial \ln \left[\sinh \left(\alpha \sigma_{p}\right)\right]}{\partial(1 / T)}\right|_{\dot{\varepsilon}}
$$

The methodology proposed by Uvira and Jonas [28] was used in this work to determine the variables. The mean value of the slopes was taken as the value of $n$ which was found to be 4.25, showed in Figure 2(a), in agreement with [29]. The value of $\left(Q_{d e f}\right)$ can be derived from the slopes in a plot of the $\ln (\varepsilon)$ versus $\ln \left[\sinh \left(\alpha \sigma_{p}\right)\right]$ versus $1 / T$, showed in Figure 2(b). The value of the $\left(Q_{d e t}\right)$ of 347 $\mathrm{kJ} / \mathrm{mol}$ was determined by averaging under different strain rates. Our previous work [4] show in more details the variables determinations. After $Q, a, n$, and $A$ were determined, they were substituted into Equation (2) to obtain the constitutive equation, including the $Z$ parameter, as expressed by Equation (6).

$$
\sigma_{p}=83.33\left[\sinh ^{-1}\left(\frac{Z}{5.51 \times 10^{-11}}\right)^{0.24}\right]
$$

\subsection{DRX Kinetic Model}

Assuming that the softened fraction is equal to the DRX fraction and is described by Avrami's law, $X_{s}$ can be expressed by Equation (1) [29] [30], where $n$ is the Avrami exponent associated with the nucleation sites, $t_{0.5}$ represents the time required for $50 \%$ of the recrystallized fraction, $\sigma_{s a t}$ is the saturation stress when only DRV occurs, and $\sigma_{s s}$ is the steady-state stress. Figure 3 shows that the kinetic behavior of DRX can be described in terms of the normal sigmoidal curves of the recrystallized volume expressed as a function of time. In our previous work [4], the exponents of Avrami were determined and the presence of DRV was found, delaying the DRX kinetics, mainly at low strain rates and high temperatures. To validate this information, an analysis was made of the depth (d) and width $(w)$ of the dip in Figure 4, generated at the negative work hardening rates. Note that the negative value of the work hardening rate $(\theta)$ indicates the action of dynamic softening. Thus, the higher the parameter $w$, the higher

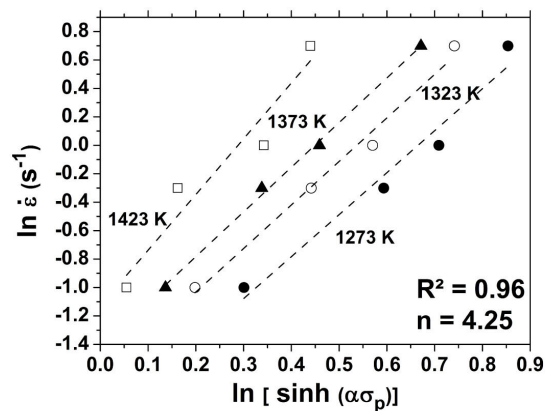

(a)

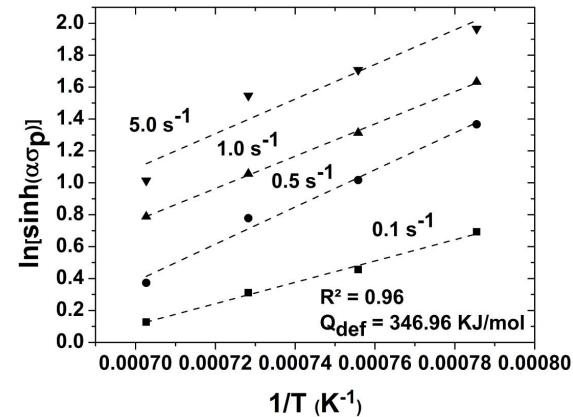

(b)

Figure 2. Variation in the hyperbolic sine function of the peak stress with (a) strain rate at different temperatures and (b) temperature at different strain rates. 


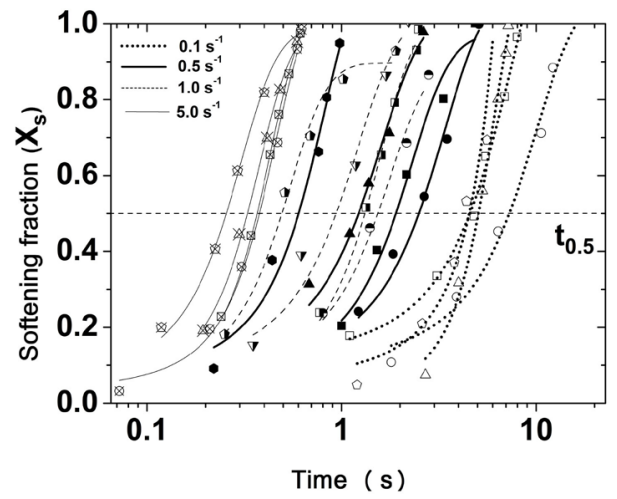

Figure 3. Dynamic softening fraction $\left(X_{s}\right)$ curves as a function of the deformation time under varying temperatures and strain rates.

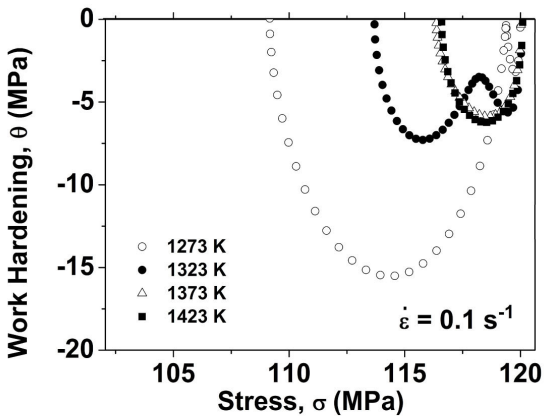

(a)

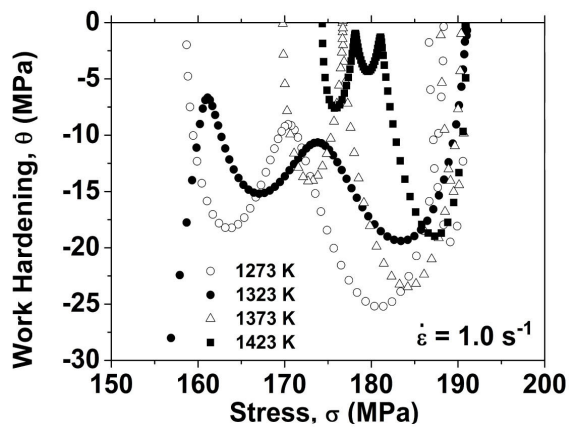

(c)

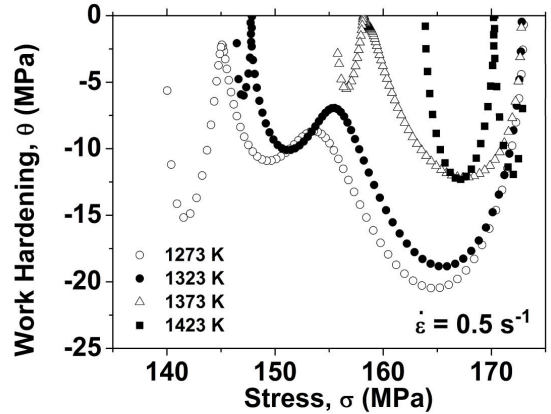

(b)

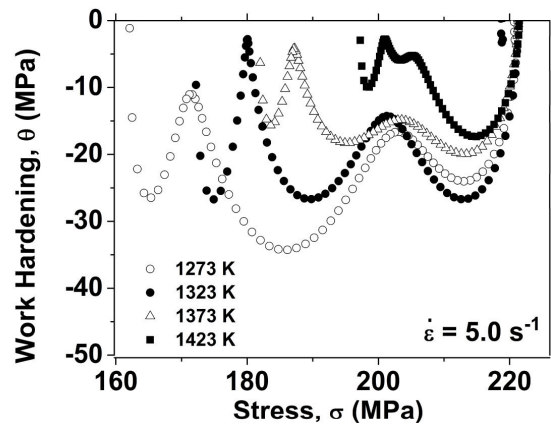

(d)

Figure 4. $\theta$ vs $\sigma$ curve only of the region of dynamic softening at strain rates of: (a) $0.1 \mathrm{~s}^{-1}$; (b) $0.5 \mathrm{~s}^{-1}$; (c) $1.0 \mathrm{~s}^{-1}$; (d) $5.0 \mathrm{~s}^{-1}$.

the dynamic softening rate of the material. On the other hand, the greatest depth occurred in the condition of low temperature and high strain rate $\left(1273 \mathrm{~K}\right.$ and $\left.5 \mathrm{~s}^{-1}\right)$, with $d \sim 35 \mathrm{MPa}$, indicating greater resistance to dynamic softening, with low $n$ $(n \sim 1.9)$.

\subsection{Corrosion Behavior}

Figure 5(a) and Figure 5(b) show the potentiodynamic anodic polarization curves obtained in $\mathrm{NaCl}$ for the $316 \mathrm{~L}$ specimens after thermomechanical processing. The results of the polarization studies are listed in Table 1 and Table 2, 


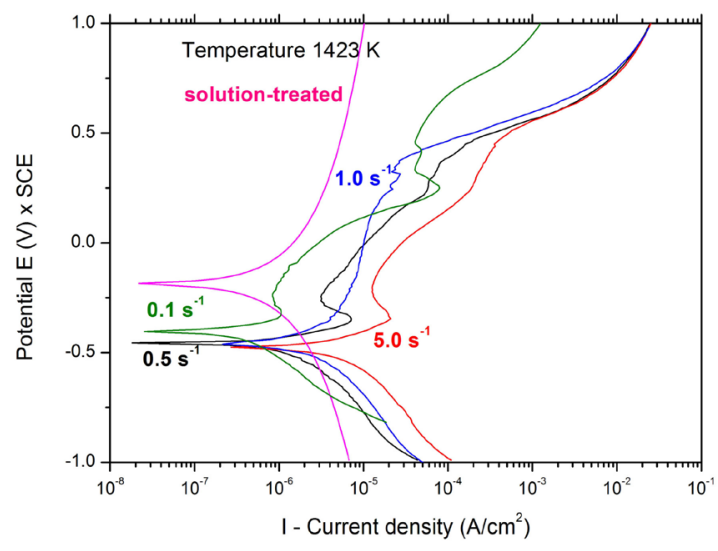

(a)

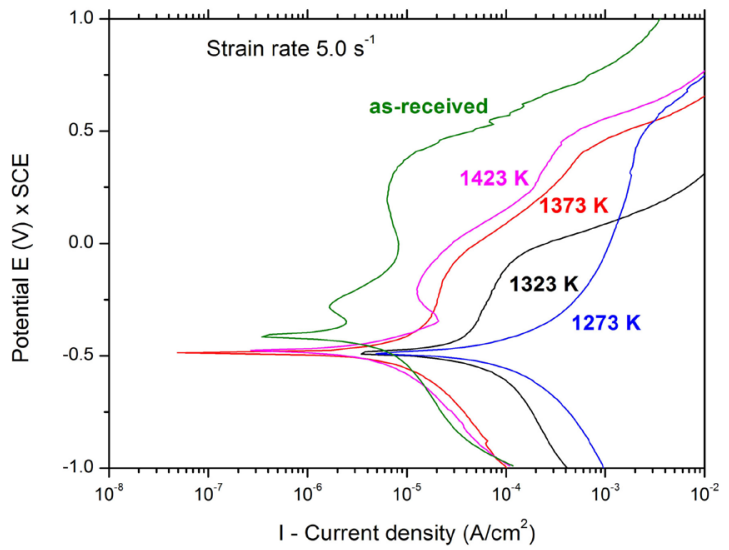

(b)

Figure 5. Potentiodynamic polarization curves in the $\mathrm{NaCl}$ cathode environment. (a) Constant temperature of $1423 \mathrm{~K}$ at various strain rates; (b) Constant strain rate of $5.0 \mathrm{~s}^{-1}$ at various temperatures.

Table 1. Potentiodynamic polarization parameters obtained from the AISI $316 \mathrm{~L}$ stainless steel at a constant temperature of $1423 \mathrm{~K}$.

\begin{tabular}{ccccc}
\hline Sample & $E_{\text {corr }}(m V)$ & $E_{p}(m V)$ & $I_{\text {corr }}(\mu A)$ & Grain size $(\mu m)$ \\
\hline Solution-treated & -189.34 & - & 10.720 & 64.00 \\
$0.1 \mathrm{~s}^{-1}$ & -397.71 & 514.37 & 0.753 & 13.43 \\
$0.5 \mathrm{~s}^{-1}$ & -463.27 & 465.61 & 1.404 & 11.85 \\
$1.0 \mathrm{~s}^{-1}$ & -465.84 & 389.20 & 0.856 & 10.57 \\
$5.0 \mathrm{~s}^{-1}$ & -478.49 & 462.29 & 8.204 & 7.35 \\
\hline
\end{tabular}

Table 2. Potentiodynamic polarization parameters obtained from the AISI $316 \mathrm{~L}$ stainless steel at a constant strain rate of $5.0 \mathrm{~s}^{-1}$.

\begin{tabular}{ccccc}
\hline Sample & $E_{\text {corr }}(\mathrm{mV})$ & $E_{p}(\mathrm{mV})$ & $I_{\text {corr }}(\mu A)$ & Grain size $(\mu \mathrm{m})$ \\
\hline As-received & -407.00 & 404.69 & 1.004 & 35.00 \\
$1273 \mathrm{~K}$ & -488.57 & 501.30 & 107.200 & 5.47 \\
$1323 \mathrm{~K}$ & -485.39 & -31.53 & 20.226 & 5.85 \\
$1373 \mathrm{~K}$ & -485.23 & 415.00 & 52.959 & 7.22 \\
$1423 \mathrm{~K}$ & -478.49 & 462.29 & 8.204 & 7.35 \\
\hline
\end{tabular}


which comprise the corrosion potential $\left(E_{\text {corr }}\right)$, critical pitting potential $\left(E_{p}\right)$, and corrosion-current density $\left(I_{\text {corr }}\right)$ values under two conditions: one with a constant temperature of $1423 \mathrm{~K}$ and various values of strain rate and another with a constant strain rate of $5.0 \mathrm{~s}^{-1}$ at various temperatures. In general, the data reveal a decrease in $E_{c o r r}$ and $E_{p}$ with the increase in the strain rate and decrease in the temperature.

\section{Discussion}

The flow curves of the $316 \mathrm{~L}$ austenitic stainless-steel alloy shown in Figure 1 illustrate the general deformation rule of metal materials, which involves three stages: work hardening, softening, and steady state. In the first part of the curves, exhibit work hardening at the early stage of deformation is higher in lower temperature and higher strain-rates, this behavior is more obvious in Figure 4, where the lower strain-rate shown a lower work hardening regarding the other curves. The phenomena is associated with generation of dislocation density during initial stages of hot working whereas DRV proceeds slowly by rearrangement/realignment of generated dislocation density until the critical dislocation density is attained for triggering DRX [31]. After the peak, a material undergoes a large plastic deformation in higher strain-rate and lower temperature, in the other hand, in higher temperatures and lower strain-rates the slope of the softening curves was less pronounced, easily seen in Figure 3, probably associated with competition between DRX and DRV [32]. Under these conditions, the flow-stress curves show a steady-state flow stress with DRV characteristics, which can be attributed to the balance between the work hardening enhanced by the $\mathrm{CrNiN}$ phase and dynamic restoration, as shown in Figure 1(a) and Figure 1(b). Figure 6(a) shows the phase diagram calculated by using the FSteel data base in the FactSage software and it can be seen the presence of chromium nitride, formed in the temperature range between 1223 and $1373 \mathrm{~K}$, and in Figure 6 (b) shows the presence of precipitates at the grain boundaries (possibly chromium nitride). The microstructural evolution during the hot process is shown in Figure 7 under the conditions of $1423 \mathrm{~K}$ and strain rate of $0.1 \mathrm{~s}^{-1}$ with DRV microstructural characteristics.

Similar flow behavior has been reported in other low to medium stacking fault energy (SFE) materials [33] [34] during DRX. This value favors the thermally activated mechanisms, which modify the deformed structure and evolution of the dislocation density, render DRV more effective, and delay the onset of DRX. Figure 3 show that slope increases with increasing temperature and strain rate except that under the conditions of high DRV rate, which delay the DRX kinetics, for example, the conditions at 1423 and $1373 \mathrm{~K}$ at a strain rate of $0.1 \mathrm{~s}^{-1}$, as shown in Figure 4(a).

With regard to the corrosion behavior, Figure 5(a) and Table 1 show the conditions at $1423 \mathrm{~K}$ and strain rate of $0.1 \mathrm{~s}^{-1}$ with $E_{\text {corr }}=-397.71 \mathrm{mV}, E_{p}=$ $514.37 \mathrm{mV}$, and $I_{\text {corr }}=0.753 \mu \mathrm{A}$, which are the highest values among all conditions, indicating high corrosion resistance. Generally, the regions of high 


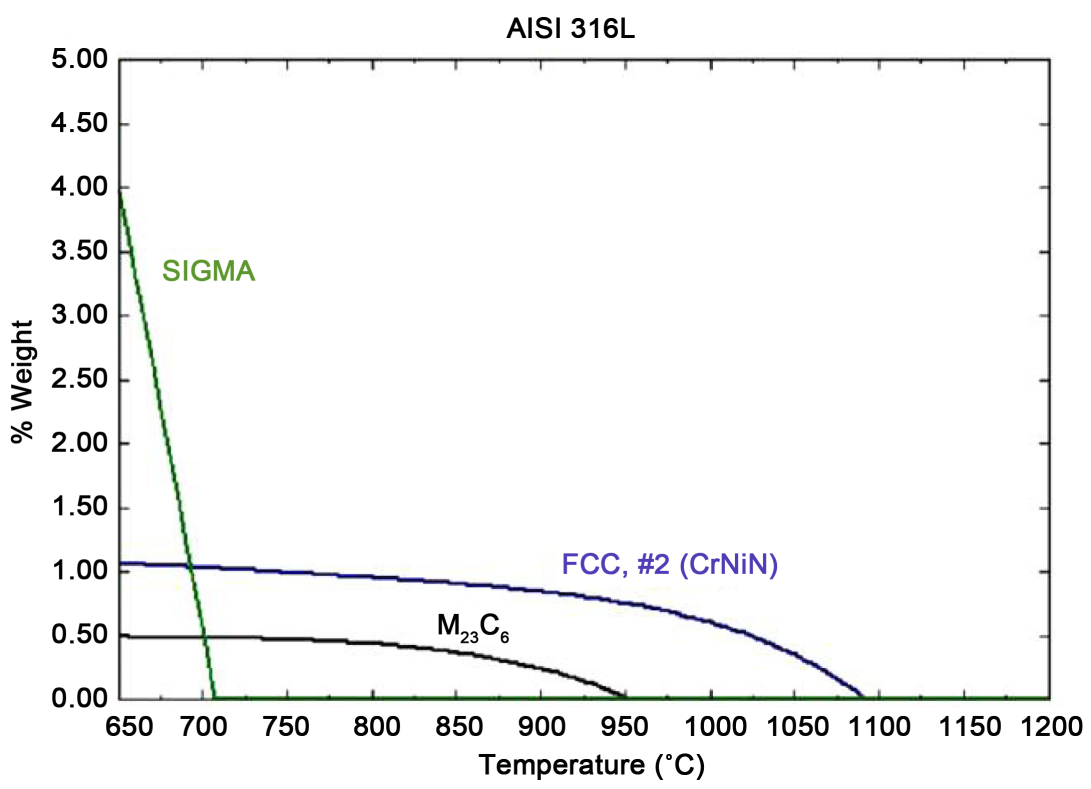

(a)

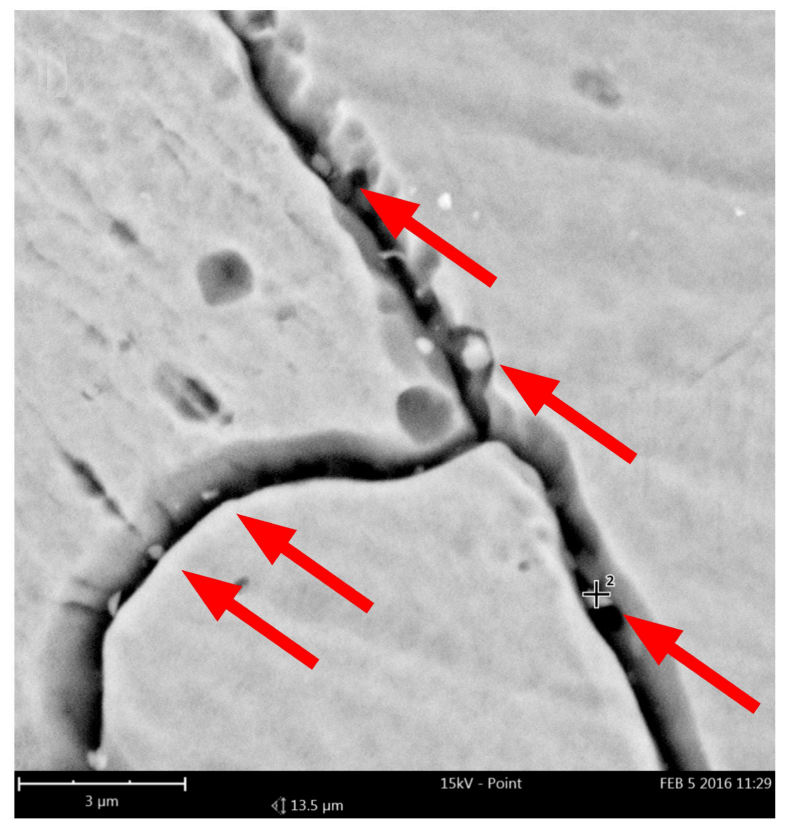

(b)

Figure 6. (a) Thermodynamic calculation of the equilibrium diagram using the FactSage of the as-received samples as a function of temperature; (b) SEM microstructure analysis under the conditions of $1423 \mathrm{~K}$, strain rate of $0.1 \mathrm{~s}^{-1}$, and $\varepsilon=3.5$, indicating the precipitates (see the arrows).

temperature and low strain rate offer good workability with a refined final microstructure containing delayed dynamically recrystallized grains. Figure 8(a) shows the microstructure under the conditions of $1423 \mathrm{~K}$ at a strain rate at $0.1 \mathrm{~s}^{-1}$. No evidence of localized corrosion appears, which is favored by the presence of CrNiN, according to the equilibrium diagram and microstructure shown in Figure 6 [35]. 

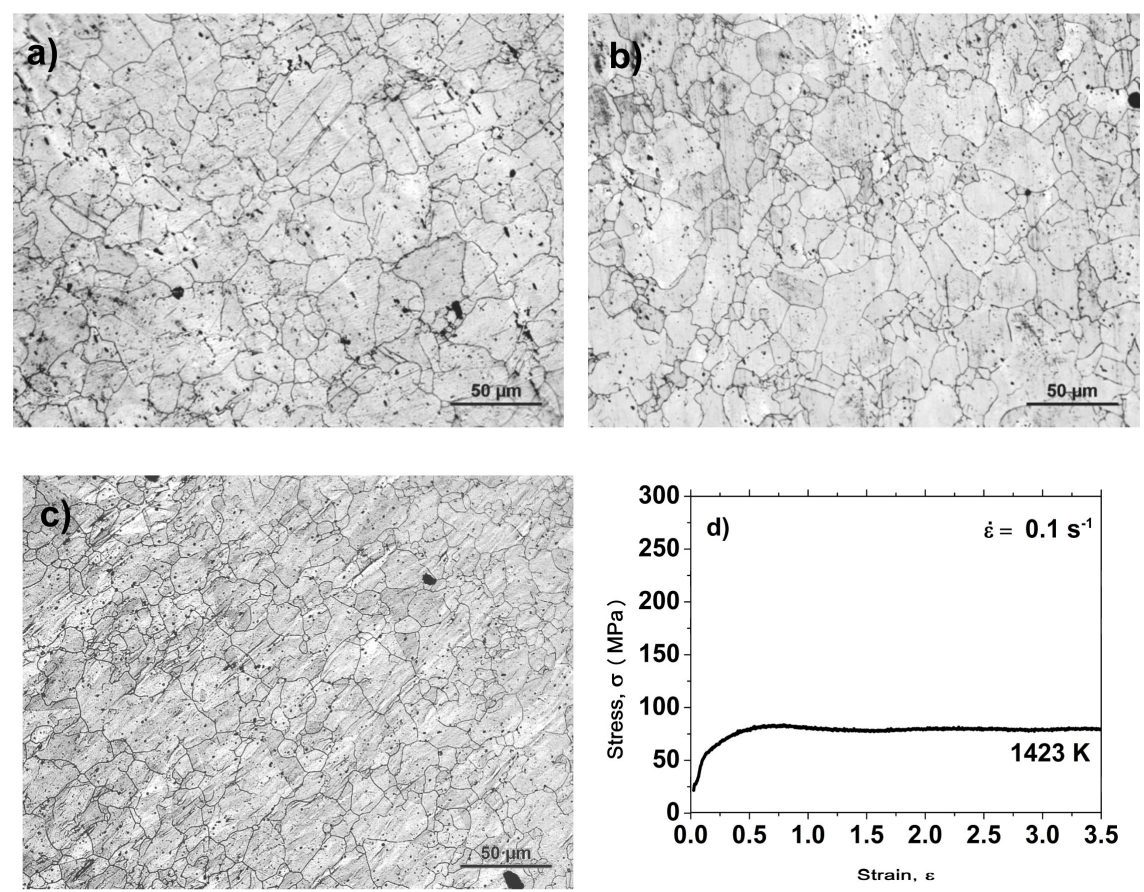

Figure 7. Microstructure under hot torsion under the condition of $1423 \mathrm{~K} / 0.1 \mathrm{~s}^{-1}$ at strain values of (a) 0.4 ; (b) 1.5; and (c) 3.5; (d) Stress-strain curve.
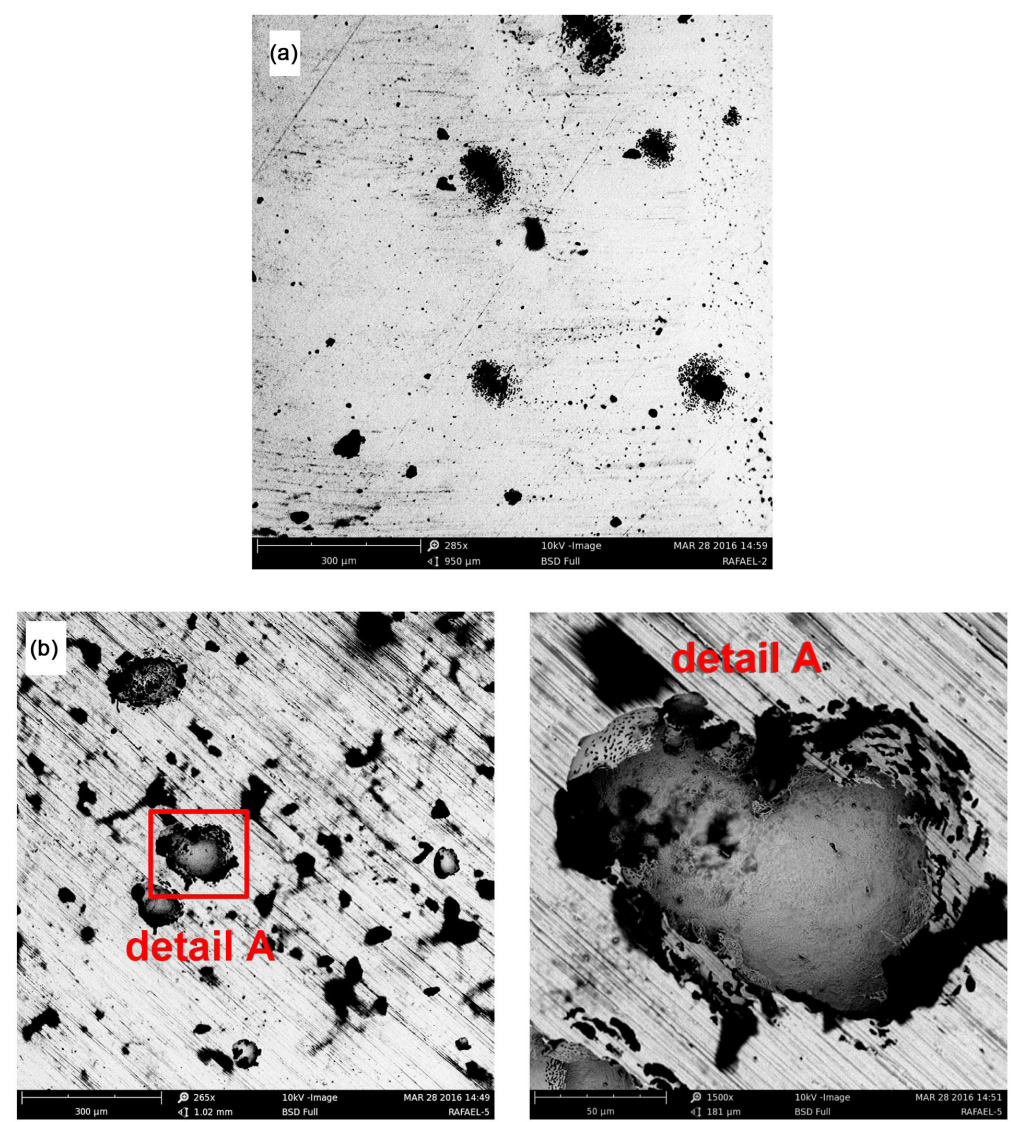

Figure 8. Microstructure at hot torsion under the condition of (a) $1423 \mathrm{~K} / 0.1 \mathrm{~s}^{-1}$ and (b) $1273 \mathrm{~K} / 5.0 \mathrm{~s}^{-1}$. 
The sample at $5.0 \mathrm{~s}^{-1}$ at $1423 \mathrm{~K}$ demonstrated higher $I_{\text {corr }}$ of $8204 \mu \mathrm{A}$, indicating higher susceptibility to corrosion among the deformation rates processed at the same temperature. By analyzing the flow curves, this condition occurs because it is the last to reach steady state, indicating the end of recrystallization. The other samples at the same processing temperature achieve recrystallization before the 2.5 deformation, followed by grain growth, as listed in Table 1 . The condition of $5.0 \mathrm{~s}^{-1} / 1423 \mathrm{~K}$ demonstrates a grain size of $7.35 \mu \mathrm{m}$. Usually, the increase in the fine grain size increase the number of grain boundaries leads to an increase in anodic reactions, decreasing the corrosion resistance [19].

Figure 5(b) and Table 2 show that the same conditions of $5.0 \mathrm{~s}^{-1}$ and $1423 \mathrm{~K}$ demonstrate lower $I_{\text {corr }}$ of $8.204 \mu \mathrm{A}$, indicating lower susceptibility to corrosion of the materials among the process temperatures at the same strain rate of $5.0 \mathrm{~s}^{-1}$ because of the larger grain size of $7.35 \mu \mathrm{m}$. The sample processed at a strain rate of $5.0 \mathrm{~s}^{-1}$ and temperature of $1273 \mathrm{~K}$ exhibits the highest value of $I_{\text {corr }}(107.200$ $\mu \mathrm{A})$. Figure $8(\mathrm{~b})$ shows severe corrosion with pits with a diameter of approximately $100 \mu \mathrm{m}$. Analysis of the flow curves indicate that this is due to the fact that this $1273 \mathrm{~K}$ condition at $5.0 \mathrm{~s}^{-1}$ strain rate is the first to reach the steady state, indicating the end of recrystallization, as well as due to the $5.47 \mu \mathrm{m}$ refined grains. The condition at $1373 \mathrm{~K}$ at the same deformation rate reaches recrystallization after 3.5 deformation, as shown in Figure 2, with less refined grains of $7.22 \mu \mathrm{m}$, thereby increasing its corrosion resistance, i.e., $I_{c o r r}=52.959 \mu \mathrm{A}$.

In general, the electrochemical results listed in Table 1 and Table 2 clearly indicate that well-recrystallized grain structures with thick grain boundaries are formed at 1373 and $1423 \mathrm{~K}$ and low strain rates of 0.1 and $0.5 \mathrm{~s}^{-1}$. These same conditions are strongly driven by DRV, which does not favor a larger grain refinement and favors the corrosion resistance of the material. On the other hand, the other samples are subjected to DRX or by competition with the DRX/DRV mechanisms, which favor a larger grain refinement, thus increasing the corrosion susceptibility. In general, an increase in the quantity of grain boundaries leads to an increase in the anodic reaction and causes a decrease in $E_{\text {corr }}$ and $I_{\text {corr }}$ [36]. Thus, a large number of grain boundaries contribute to a low corrosion resistance. During hot processing, the grain sizes increase with increasing temperature variation and decreasing strain rate (Table 1 and Table 2). The samples with recrystallized grains show a higher degree of corrosion than the received samples, except at $1423 \mathrm{~K}$ and strain rate of $0.1 \mathrm{~s}^{-1}$, which is attributed to the reduction in the instability of the passive film [37]. The solution-treated samples exhibit good corrosion resistance but do not have refined grains, i.e., the grain size is $35.00 \mu \mathrm{m}$. Therefore, they exhibit low mechanical properties.

From the aforementioned results and discussion, we demonstrate that good workability implies that the alloy can be thermomechanically processed into different shapes such as pipelines and hospital equipment. The hot-deformation process can significantly refine the grain size and enhance the corrosion resistance. However, the deformation temperature should be higher than $1373 \mathrm{~K}$ at low strain rates to obtain good mechanical properties without reduction in the 
corrosion resistance of the $316 \mathrm{~L}$ austenitic stainless steel. The best processing route identified in this study is $1423 \mathrm{~K}_{\text {at }} 0.1 \mathrm{~s}^{-1}$. Some results presented in the literature lead to the same understanding regarding the influence of processing conditions on the corrosion susceptibility, such as [14] [19] [20].

\section{Conclusions}

In this work, the hot deformation behavior, namely, DRX behavior, and corrosion resistance of the $316 \mathrm{~L}$ austenitic stainless steel alloy was investigated. Our conclusions are as listed as follows.

1) The true stress-strain curves of the $316 \mathrm{~L}$ austenitic stainless steel under various conditions show a DRX characteristic with softening promoted by intense DRV behavior in relation to the strain rate and temperature. The flow stress increases with decreasing deformation temperature and increasing strain rate.

2) The hot-deformation process significantly refines the microstructure, but the hot deformation at low temperature $(1273-1323 \mathrm{~K})$ and high strain rate (5.0 $-1.0 \mathrm{~s}^{-1}$ ) slightly reduced the corrosion resistance.

3) The final optimized deformation process is achieved at the deformation temperature of $1423 \mathrm{~K}$ and strain rate of $0.1 \mathrm{~s}^{-1}$ where a completely recrystallized and homogeneously distributed microstructure is obtained, indicating good mechanical and corrosion properties.

\section{Acknowledgements}

The authors acknowledge the financial support of the Brazilian research funding agencies FAPEMA (Maranhão Foundation for Scientific Research and Development), $\mathrm{CNPq}$ and CAPES. We are also grateful for the technical support provided by Prof. MSc. Thiago Oliveira.

\section{Conflicts of Interest}

The authors declare no conflicts of interest regarding the publication of this paper.

\section{References}

[1] Baddoo, N.R. (2008) Stainless Steel in Construction: A Review of Research, Applications, Challenges and Opportunities. Journal of Constructional Steel Research, 64, 1199-1206. https://doi.org/10.1016/j.jcsr.2008.07.011

[2] Lo, K.H., Shek, C.H. and Lai, J.K.L. (2009) Recent Developments in Stainless Steels. Materials Science and Engineering. R: Reports, 65, 39-104. https://doi.org/10.1016/j.mser.2009.03.001

[3] Byun, T.S., Hashimoto, N. and Farrell, K. (2004) Temperature Dependence of Strain Hardening and Plastic Instability Behaviors in Austenitic Stainless Steels. Acta Materialia, 52, 3889-3899. https://doi.org/10.1016/j.actamat.2004.05.003

[4] Ferreira, R.P., Silva, E.S., Nascimento, C.C., Rodrigues, S.F., Aranas Jr., C., Leal, V.S. and Reis, G.S. (2016) Thermomechanical Behavior Modeling of a Cr-Ni-Mo-Mn-N 
Austenitic Stainless Steel. Materials Sciences and Applications, 7, 803. https://doi.org/10.4236/msa.2016.712062

[5] Nkhoma, R.K.C., Siyasiya, C.W. and Stumpf, W.E. (2014) Hot Workability of AISI 321 and AISI 304 Austenitic Stainless Steels. Journal of Alloys and Compounds, 595, 103-112. https://doi.org/10.1016/j.jallcom.2014.01.157

[6] Shyr, T.W., Shie, J.W., Huang, S.J., Yang, S.T. and Hwang, W.S. (2010) Phase Transformation of 316 L Stainless Steel from Wire to Fiber. Materials Chemistry and Physics, 122, 273-277. https://doi.org/10.1016/j.matchemphys.2010.02.048

[7] Wasnik, D.N., Dey, G.K., Kain, V. and Samajdar, I. (2003) Precipitation Stages in a 316 L Austenitic Stainless Steel. Scripta Materialia, 49, 135-141. https://doi.org/10.1016/S1359-6462(03)00220-3

[8] Cabrera, E.S. (2001) High Temperature Deformation of 316 L Stainless Steel. Materials Science and Technology, 17, 155-161. https://doi.org/10.1179/026708301101509944

[9] Guo, B., Ji, H., Liu, X., Gao, L., Dong, R., Jin, M. and Zhang, Q. (2012) Research on Flow Stress during Hot Deformation Process and Processing Map for 316 LN Austenitic Stainless Steel. Journal of Materials Engineering and Performance, 21, 1455-1461. https://doi.org/10.1007/s11665-011-0031-0

[10] Jafari, M. and Najafizadeh, A. (2008) Comparison between the Methods of Determining the Critical Stress for Initiation of Dynamic Recrystallization in 316 Stainless Steel. Journal of Materials Science \& Technology, 24, 840.

[11] Li, S.X., He, Y.N., Yu, S.R. and Zhang, P.Y. (2013) Evaluation of the Effect of Grain Size on Chromium Carbide Precipitation and Intergranular Corrosion of $316 \mathrm{~L}$ Stainless Steel. Corrosion Science, 66, 211-216. https://doi.org/10.1016/j.corsci.2012.09.022

[12] Yi, Y., Cho, P., Al Zaabi, A., Addad, Y. and Jang, C. (2013) Potentiodynamic Polarization Behaviour of AISI Type 316 Stainless Steel in $\mathrm{NaCl}$ Solution. Corrosion Science, 74, 92-97. https://doi.org/10.1016/j.corsci.2013.04.028

[13] Peng, X., Zhou, X. and Hua, X. (2016) Effect of Grain Size on Susceptibility to Intergranular Corrosion of 316 LN Stainless Steel. Journal of Chinese Society for Corrosion and Protection, 36, 25-30.

[14] Kingkam, W., Zhao, C.-Z., Li, H., Zhang, H.-X. and Li, Z.-M. (2018) Hot Deformation and Corrosion Resistance of High-Strength Low-Alloy Steel. Acta Metallurgica Sinica (English Letters), 32, 495-505. https://doi.org/10.1007/s40195-018-0797-2

[15] Liu, G., Xie, W., Wei, G.B., Yang, Y., Liu, J.W., Xu, T.C., Xie, W.D. and Peng, X.D. (2018) Dynamic Recrystallization Behavior and Corrosion Resistance of a Dual-Phase Mg-Li Alloy. Materials, 11, 408. https://doi.org/10.3390/ma11030408

[16] Jafari, M. and Najafizadeh, A. (2009) Correlation between Zener-Hollomon Parameter and Necklace DRX during Hot Deformation of 316 Stainless Steel. Materials Science and Engineering. A, 501, 16-25. https://doi.org/10.1016/j.msea.2008.09.073

[17] Chen, X.M., Lin, Y.C., Chen, M.S., Li, H.B., Wen, D.X., Zhang, J.L. and He, M. (2015) Microstructural Evolution of a Nickel-Based Superalloy during Hot Deformation. Materials \& Design, 77, 41-49. https://doi.org/10.1016/j.matdes.2015.04.004

[18] Han, Y., Wu, H., Zhang, W., Zou, D., Liu, G. and Qiao, G. (2015) Constitutive Equation and Dynamic Recrystallization Behavior of As-Cast 254SMO Super-Austenitic Stainless Steel. Materials \& Design, 69, 230-240. https://doi.org/10.1016/j.matdes.2014.12.049

[19] Kingkam, W. (2018) Effect of Temperature during Hot Deformation on the Elec- 
trochemical Behavior of HSLA Pipeline Steels. International Journal of Electrochemical Science, 13, 2766-2778. https://doi.org/10.20964/2018.03.15

[20] Zhang, E., Ge, Y. and Qin, G. (2018) Hot Deformation Behavior of an Antibacterial Co-29Cr-6Mo-1.8Cu Alloy and Its Effect on Mechanical Property and Corrosion Resistance. Journal of Materials Science \& Technology, 34, 523-533. https://doi.org/10.1016/j.jmst.2016.09.025

[21] Samantaray, D., Mandal, S., Jayalakshmi, M., Athreya, C.N., Bhaduri, A.K. and Sarma, V.S. (2014) New Insights into the Relationship between Dynamic Softening Phenomena and Efficiency of Hot Working Domains of a Nitrogen Enhanced $316 \mathrm{~L}$ (N) Stainless Steel. Materials Science and Engineering: A, 598, 368-375. https://doi.org/10.1016/j.msea.2013.12.105

[22] Torganchuk, V., Glezer, A., Belyakov, A. and Kaibyshev, R. (2018) Deformation Behavior of High-Mn TWIP Steels Processed by Warm-to-Hot Working. Metals, 8, 415. https://doi.org/10.3390/met8060415

[23] Mcqueen, H.J. (2004) Development of Dynamic Recrystallization Theory. Materials Science and Engineering: A, 387, 203-208. https://doi.org/10.1016/j.msea.2004.01.064

[24] Fields, D.S. and Backofen, W.A. (1957) Determination of Strain Hardening Characteristics by Torsion Testing. Proceeding of American Society for Testing and Materials, 57, 1259-1272.

[25] American Society for Testing and Materials (ASTM) E122 (2013) Standard Test Methods for Determining Average Grain Size.

[26] Wolynec, S. (2003) Técnicas Eletroquímicas em Corrosão. Vol. 49. Edusp.

[27] Sellars, C.M. and Tegart, W.J.M. (1966) La relation entre la resistance et la structure dans la deformation a chaud. Memoires Scientifiques de la Revue de Metallurgie, 63, 731-746. https://doi.org/10.1051/metal/196663030225

[28] Laasraoui, A. and Jonas, J.J. (1991) Prediction of Steel Flow Stresses at High Temperatures and Strain Rates. Metallurgical and Materials Transactions A, 22, 1545-1558. https://doi.org/10.1007/BF02667368

[29] Uvira, J.L. and Jonas, J.J. (1968) Hot Compression of Armco Iron and Silicon Steel. Transactions of the Metallurgical Society of AIME, 242, 1619-1626.

[30] Rodrigues, S.F., Silva, E.S., Reis, G.S., Sousa, R.C.D. and Balancin, O. (2014) Prediction of Hot Flow Plastic Curves of ISO 5832-9 Steel Used as Orthopedic Implants. Materials Research, 17, 436-444. https://doi.org/10.1590/S1516-14392014005000001

[31] Kumar, S., Raghu, T., Pinaki, P., Bhattacharjee, G., Rao, A. and Borah, U. (2017) Work Hardening Characteristics and Microstructural Evolution during Hot Deformation of a Nickel Superalloy at Moderate Strain Rates. Journal of Alloys and Compounds, 709, 394-409. https://doi.org/10.1016/j.jallcom.2017.03.158

[32] Llanos, L., Pereda, B., Lopez, B. and Rodriguez-Ibabe, J.M. (2016) Hot Deformation and Static Softening Behavior of Vanadium Microalloyed High Manganese Austenitic Steels. Materials Science and Engineering. A, 651, 358-369. https://doi.org/10.1016/j.msea.2015.10.123

[33] Xu, T.C., Peng, X.D., Qin, J., Chen, Y.F., Yang, Y. and Wei, G.B. (2015) Dynamic Recrystallization Behavior of Mg-Li-Al-Nd Duplex Alloy during Hot Compression. Journal of Alloys and Compounds, 639, 79-88. https://doi.org/10.1016/j.jallcom.2015.03.144

[34] Wendler, M., Hauser, M., Fabrichnaya, O., Kruger, L., Wei, A. and Mola, J. (2015) Thermal and Deformation-Induced Phase Transformation Behavior of Fe-15Cr$3 \mathrm{Mn}-3 \mathrm{Ni}-0.1 \mathrm{~N}-(0.05-0.25) \mathrm{C}$ Austenitic and Austenitic-Martensitic Cast Stainless 
Steels. Materials Science and Engineering A, 645, 28-39. https://doi.org/10.1016/j.msea.2015.07.084

[35] Song, R., Xiang, J. and Hou, D. (2011) Characteristics of Mechanical Properties and Microstructure for $316 \mathrm{~L}$ Austenitic Stainless Steel. International Journal of Iron and Steel Research, 60, 117-119.

[36] Sobrinho, J.H.O.S., Rodrigues, S.F., Silva, E.S., Reis, G.S., Sousa, R.C., Leal, V.S. and Mercury, J.M.R. (2015) Plastic Instability in ISO 5832-9 High-Nitrogen Austenitic Stainless Steel. ISIJ International, 55, 670-678. https://doi.org/10.2355/isijinternational.55.670

[37] Hiromoto, S., Onodera, E., Chiba, A., Asami, K. and Hanawa, T. (2005) Microstructure and Corrosion Behavior in Biological Environments of the New Forged Low-Ni Co-Cr-Mo Alloys. Biomaterials, 26, 4912-4923.

https://doi.org/10.1016/j.biomaterials.2005.01.028 